\section{Anterior Minithoracotomy: Is It Useful To Use Prosthetic Materials in Routine Surgery?}

\section{TO THE EDITORS:}

We read with interest the article of Pettiford and colleagues about their anterior minithoracotomy approach, and we would like to congratulate them for their wellwritten paper. ${ }^{1}$

The surgical technique they describe reminds us of the approach described by Rienhoff in 1947, modified in order not to divide the thoracoacromial neurovascular bundle laterally and with addition of an operative access port. ${ }^{2}$

According to what was described by Chamberlain and colleagues in 1966, the authors resect subperiosteally the third anterior aspect of the third rib then resect also a $1.5-\mathrm{cm}$ segment of the anterolateral fourth rib. ${ }^{3}$

At the conclusion of the surgical procedure the authors reconstruct chest wall using a prosthetic mesh (absorbable or not).

According to our experience using lateral muscle-sparing thoracotomy (as described by Noirclerc in 1973), we are able to perform almost all the procedures (including extrapleural pneumonectomy for malignant mesothelioma and lower lobectomy with or without bronchial or vascular reconstructions), with good cosmetic results. ${ }^{4}$

The incision is usually $12-14 \mathrm{~cm}$ in length for routine surgery, with good cosmetic result (the incision being placed on the lateral thoracic wall, as an ideal prolongation of the submammary sulcus), and prosthetic material is not required at any stage to close our access to the chest cavity.
Prosthetic materials are expensive, they need to be properly placed, thus prolonging operative time, and they may cause adverse effects (especially if nonabsorbable meshes are used).

Our opinion is that use of prosthesis should be limited to chest wall resections and reconstruction when they are necessary.

Moreover, we would like to ask some questions to the authors:

When and how often is it indicated to place the prosthesis?

What are the long-term aesthetic results?

Have they studied patient satisfaction, especially in the female population?

Paolo Scanagatta, MD, Sava Durkovic, MD, and Ugo Pastorino, MD

Division of Thoracic Surgery, National Cancer Institute, Milan, Italy

e-mail: paoscan@hotmail.com

Published Online: 20 November 2010

(C) Society of Surgical Oncology 2010

\section{REFERENCES}

1. Pettiford BL, Schuchert MJ, Abbas G, et al. Anterior minithoracotomy: a direct approach to the difficult hilum for upper lobectomy, pneumonectomy, and sleeve lobectomy. Ann Surg Oncol. 2010;17:123-8.

2. Rienhoff WF. The present status of the surgical treatment of carcinoma of the lung. Ann Surg. 1947;125:541-64.

3. McNeill TM, Chamberlain JM. Diagnostic anterior mediastinotomy. Ann Thorac Surg. 1966;2:532-9.

4. Noirclerc M, Dor V, Chauvin G, et al. La thoracotomie laterale large sans section musculaire. Ann Chir Thorac Cardiovasc. $1973 ; 12: 181-4$. 